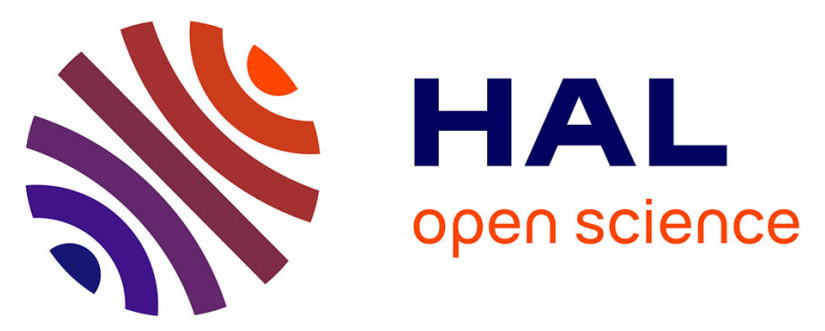

\title{
Preventive Beneficial Effect of an Aqueous Extract of Phyllanthus amarus Schum. and Thonn. (Euphorbiaceae) on DOCA-Salt-Induced Hypertension, Cardiac Hypertrophy and Dysfunction, and Endothelial Dysfunction in Rats
}

\author{
N'Guessan Alain Yao, Zahid Rasul Niazi, Iveta Najmanová, Mamadou \\ Kamagaté, Amissi Said, Philippe Chabert, Cyril Auger, Henri Die-Kakou, \\ Valérie Schini-Kerth
}

\section{To cite this version:}

N'Guessan Alain Yao, Zahid Rasul Niazi, Iveta Najmanová, Mamadou Kamagaté, Amissi Said, et al.. Preventive Beneficial Effect of an Aqueous Extract of Phyllanthus amarus Schum. and Thonn. (Euphorbiaceae) on DOCA-Salt-Induced Hypertension, Cardiac Hypertrophy and Dysfunction, and Endothelial Dysfunction in Rats. Journal of Cardiovascular Pharmacology, 2020, 75 (6), pp.573 - 583. 10.1097/fjc.0000000000000825 . hal-03033829

\section{HAL Id: hal-03033829 \\ https://cnrs.hal.science/hal-03033829}

Submitted on 1 Dec 2020

HAL is a multi-disciplinary open access archive for the deposit and dissemination of scientific research documents, whether they are published or not. The documents may come from teaching and research institutions in France or abroad, or from public or private research centers.
L'archive ouverte pluridisciplinaire HAL, est destinée au dépôt et à la diffusion de documents scientifiques de niveau recherche, publiés ou non, émanant des établissements d'enseignement et de recherche français ou étrangers, des laboratoires publics ou privés. 
Preventive beneficial effect of an aqueous extract of Phyllanthus amarus Schum. \& Thonn. (Euphorbiaceae) on DOCA-salt-induced hypertension, cardiac hypertrophy and dysfunction, and endothelial dysfunction in rats

N'guessan Alain Yao, $\mathrm{PhD}^{* \dagger}$, Zahid Rasul Niazi, PhD*, Iveta Najmanová, PhD*, Mamadou Kamagaté, $\mathrm{MD}, \mathrm{PhD}^{\S \#}$, Amissi Said, PharmD, $\mathrm{PhD}^{*}$, Philippe Chabert, PhD , Cyril Auger, $\mathrm{PhD}^{*}$, Henri Die-Kakou, MD, $\mathrm{PhD}^{*}$, Valérie Schini-Kerth, PharmD, $\mathrm{PhD}^{\S}$

*UMR 7213 CNRS, Laboratory of Biophotonic and Pharmacology, Faculty of Pharmacy, University of Strasbourg, Illkirch, France

${ }^{\dagger}$ Department of Pharmacology, UFR-SMA, Félix Houphouët-Boigny University, Abidjan, Côte d'Ivoire

"Department of Pharmacology, UFR-SMB, Alassane Ouattara University, Bouaké, Côte d'Ivoire

${ }^{\S}$ Corresponding author: Mamadou Kamagaté, MD, PhD, Department of Pharmacology, UFRSMB, Alassane Ouattara University, Bouaké, Côte d’Ivoire, BPV 1801, Bouaké, Côte d'Ivoire, Phone: +225 09013802, E-mail address: kamadg@yahoo.fr

or Valérie Schini-Kerth, PharmD, PhD,UMR 7213 CNRS, University of Strasbourg, Faculty of Pharmacy, 74 route du Rhin, F-67401 Illkirch, France ,Phone: +333 68854127, Fax: +333 68854313, E-mail address: valerie.schini-kerth@unistra.fr 


\section{Funding}

The Service of Cooperation and Cultural Action of French Embassy of Côte d'Ivoire (grant $\mathrm{N}^{\circ}$ 767294B and 796998H) and the Ministry of Higher Education and Scientific Research of Côte d'Ivoire (grant $N^{\circ}$ 1548/MERS/DB/SD-BHCI/SD/CBK du 26/08/2015) provided the funding.

\section{Conflicts of interests}

The authors declare no conflicts of interest.

\section{Abstract}

This study investigated the preventive effect of an aqueous extract of the whole plant of Phyllanthus amarus (AEPA) on blood pressure, cardiac and endothelial function in the deoxycorticosterone acetate (DOCA)-salt-induced hypertensive rat model. Male Wistar rats were assigned into five groups receiving either vehicle (control and DOCA-salt), DOCA-salt combined with AEPA at 100 or $300 \mathrm{mg} / \mathrm{kg}$, or AEPA $(100 \mathrm{mg} / \mathrm{kg})$ alone for 5 weeks. In addition, DOCA-salt-treated rats were allowed free access to water containing $1 \% \mathrm{NaCl}$. Systolic blood pressure (SBP), left ventricle parameters, vascular reactivity of primary mesenteric artery rings, the yascular level of oxidative stress and the level of target proteins were determined, using respectively tail-cuff sphygmomanometry, echocardiography, organ chambers, dihydroethidium staining, and immunofluorescence methods.

After 5 weeks, AEPA treatments (100 or $300 \mathrm{mg} / \mathrm{kg} / \mathrm{day})$ significantly prevented the increase in SBP in DOCA-salt rats, respectively by about 24 and $21 \mathrm{mmHg}$, improved cardiac diastolic function, and reduced significantly the increased posterior and septum diastolic wall thickness and the left ventricle mass in hypertensive rats. Moreover, the DOCA-salt-induced endothelial dysfunction, and the blunted nitric oxide- and endothelium-dependent hyperpolarizationmediated relaxations in primary mesenteric artery were improved after the AEPA treatments. 
AEPA also reduced the level of vascular oxidative stress and the expression level of target proteins (eNOS, COX-2, NADPH oxidase subunit $\mathrm{p} 22^{\text {phox }}$ ) in DOCA-salt rats.

Altogether, AEPA prevented hypertension, improved cardiac structure and function, and endothelial function in DOCA-salt rats. Such beneficial effects appear to be related, at least in part, to normalization of the vascular level of oxidative stress.

Keywords: Phyllanthus amarus, DOCA-salt, hypertension, cardiac hypertrophy, endothelial dysfunction

\section{INTRODUCTION}

Hypertension is an important public health problem, ${ }^{1}$ which can lead to major cardiovascular complications such as atherosclerosis, coronary artery diseases, congestive heart failure and stroke, in chronic situation. ${ }^{2-4}$ Previous studies have indicated that the spontaneously hypertensive rat (SHR), the angiotensin II (Ang II)-induced hypertensive rat, the Dahl saltsensitive hypertensive rat or the DOCA-salt rat are used as experimental models of human essential hypertension to better understand the underlying pathophysiology. ${ }^{5,6}$ The DOCA-salt model of hypertension is obtained following administration of a synthetic mineralocorticoid deoxycorticosterone acetate (DOCA) for several weeks to rats allowed free access to water containing high $\mathrm{NaCl}$, promoting volume overload induced hypertension with sodium retention $^{5,7}$, which is associated with a low level of renin and hypokalemia. ${ }^{5,8}$ Endothelial dysfunction, cardiac hypertrophy, renal damage, and inflammation, common deleterious effects associated with hypertension in Humans, are also observed in experimental models of hypertension. ${ }^{9,10}$ In case of hypertension-related endothelial dysfunction, the blunted endothelium-derived relaxing factors-mediated relaxations is often observed affecting both the nitric oxide (NO) and the endothelium-dependent hyperpolarization (EDH) 
components. ${ }^{11,12}$ Moreover, they are also often related to an excessive formation of reactive oxygen species (ROS), predominantly by vascular NADPH oxidase. ${ }^{13}$

Antihypertensive therapy in first line uses classic drugs, including diuretics, angiotensinconverting enzyme inhibitors, angiotensin II type 1 receptor (AT1R) blockers, calcium channel blockers and beta-blockers. However, during the last few decades, the modification of lifestyle and the use of natural products derived from plants have gained much attention in the prevention and the treatment of cardiovascular pathologies, such as high blood pressure..$^{10,14}$ Traditional medicine is managing hypertensive disease through the use of plants from the Pharmacopoeia. However, traditional healers have limited resources for the diagnosis of hypertension. Therefore, beyond suggestive signs such as recurrent vertigo, they refer to their patient's medical examinations, confirming high blood pressure prior to treatment by plants extract.

In Ivorian folk medicine, many traditional herbal preparations are offered to the population for the treatment of high blood pressure. For example, an ethnopharmacological survey conducted on markets in the district of Abidjan (Côte d'Ivoire) identified 27 antihypertensive plants commonly used by hypertensive patients, including Phyllanthus amarus (Euphorbiaceae), with a frequency of use of about $42 \% .^{15}$

Moreover, previous data have also reported that Phyllanthus amarus extract is used by most of the Ivorian local population, especially by Abbey and Krobou of Agboville (Côte d'Ivoire) as decoction of leaves or whole plant to treat hypertension and other pathologies such as diabetes, fever, malaria and stomach ulcer. ${ }^{15-17}$ Numerous studies have reported that Phyllanthus amarus extracts can induce several kinds of pharmacological activities such as anti-inflammatory, ${ }^{18}$ antioxidant, ${ }^{19}$ vasodilatation, hypotensive and antihypertensive. ${ }^{20-22}$ Preliminary pharmacological investigations have suggested the involvement of muscarinic receptors, an increased formation of endothelium-derived NO, and blockade of calcium 
channels in the mechanism of the hypotensive activity of aqueous extracts of leaves and whole plant of Phyllanthus amarus in normotensive rabbits, and the induction of diuresis in rats. $^{21,23,24}$ Moreover, the ethanolic fraction of Phyllanthus amarus promoted urinary excretion of water and $\mathrm{Na}^{+}$, which involved prostaglandins in rats. ${ }^{25}$ Furthermore, according to a recent study using high-fructose (HF) fed Wistar rats, the aqueous extracts of Phyllanthus amarus prevented cardiac and vascular damage by improving the increased level of cardiac and aortic lipids and stress markers, and also the decreased level of antioxidants defense markers such as vitamin C, superoxide dismutase and catalase. ${ }^{26}$ Although, Phyllanthus amarus is known as a potential remedy against high blood pressure, to our knowledge cardioprotective and antihypertensive effects of Phyllanthus amarus in chronic hypertension has not been assessed. Therefore, the aim of the present study was to evaluate the preventive effect of an aqueous extract of Phyllanthus amarus (AEPA) obtained by decoction of the whole plant, on hypertension, cardiac hypertrophy and endothelial dysfunction induced by DOCA-salt in rats.

\section{METHODS}

\section{Plant material and extraction procedure}

The whole plant of Phyllanthus amarus (Euphorbiaceae) was previously identified by Professor Aké-Assi Laurent (expert in botany), at the National de Floristic Center of Félix Houphouët-Boigny University (Abidjan, Côte d'Ivoire) where several samples of Phyllanthus amarus are registered, respectively under voucher specimen No. 3, 141 and 248. The website http://www.theplantlist.org has been used to check the plant name. The plant used to prepare the extract was harvested in the district of Cocody (Abidjan, Côte d'Ivoire) in April 2014, in accordance with the international convention concerning the biodiversity right. ${ }^{27,28}$ In Ivorian traditional medicine, Phyllanthus amarus is known under some vernacular name, such as 
sougnassi (Baoulé) or dè-la-kôla (Malinké). Moreover, its common name in English is carry me seed.

Phyllanthus amarus aqueous extract was prepared according to a method previously described. ${ }^{23}$ Briefly, after the harvest, the whole plants collected were washed. Next, $500 \mathrm{~g}$ of plant were put in 1 liter of distilled water and boiled for $30 \mathrm{~min}$. Thereafter, the decoction was filtered and lyophilized to obtain the powder of the aqueous extract of Phyllanthus amarus (AEPA). The extraction procedure provided $11.72 \mathrm{~g}$ of AEPA from $1 \mathrm{~kg}$ of plant. The extract was stored at $-20{ }^{\circ} \mathrm{C}$ for subsequent pharmacological studies.

\section{Animals and experimental groups}

Experiments were performed according to the US guidelines for laboratory animal use and care, previously published (publication No. 85-23, revised 1996) by the National Institutes of Health (NIH). ${ }^{29}$ Male Wistar rats (Janvier, Le Genest-Saint-Isle, France) weighing between 180 and $200 \mathrm{~g}$ were maintained under standard laboratory conditions $\left(21-22{ }^{\circ} \mathrm{C}\right)$ with dark and light cycle $(12 / 12 \mathrm{~h})$ and received on free access a standard dry pellet diet (A04, SAFE, France) and water ad libitum. Non-uniephrectomized rats were randomly assigned 7-8 rats per group, into the control group, the AEPA group, the DOCA-salt group, and the DOCA-salt + AEPA groups. The AEPA group received by gavage AEPA (100 mg/kg/day) solubilized in $\mathrm{H}_{2} \mathrm{O}$ for 6 weeks. The DOCA-salt group received subcutaneously injection of DOCA (50 $\mathrm{mg} / \mathrm{kg}$ ) in corn oil once weekly for 5 weeks. In addition, water containing $1 \% \mathrm{NaCl}$ was available to the DOCA-salt-treated rats for free access. The DOCA-salt + AEPA groups were pretreated by gavage with AEPA (100 or $300 \mathrm{mg} / \mathrm{kg} /$ day) for one week before the injection of DOCA, and, thereafter, the AEPA treatments were continued as appropriate for 5 weeks. 


\section{Blood pressure measurements}

The blood pressure analysis system (BP-2000 Serie II, Visitech Systems) was used to determine systolic blood pressure (SBP), by tail-cuff sphygmomanometry, twice weekly during 5 weeks. Prior to start of blood pressure monitoring, rats were trained daily for one week to get used to the system. Blood pressure was always monitored at 9 a.m and included at least 12 measurements.

\section{Echocardiographic studies}

After 5 weeks of treatment, prior to start echocardiographic studies, rats were anaesthetized by intraperitoneal injection of pentobarbital $(50 \mathrm{mg} / \mathrm{kg})$. Cardiac structure and function were subsequently obtained using the transthoracic echocardiography (Phillips Sonos 5500 equipped with a 12-MHz phased-array transducer). Two-dimensional short axis views of the left ventricle and M-mode tracings were recorded through anterior and posterior left ventricle (LV) walls at the papillary muscle level. LV end-diastolic diameter (LVEDD), LV endsystolic diameter (LVESD), posterior and septum diastolic wall thickness (PWT and SWT, respectively) were determined for characterization of the cardiac left ventricle. In addition, the LV ejection fraction (\% LVEF), left ventricular mass (LVM) and cardiac output (CO) were determined. ${ }^{9}$ In addition, heart rate (HR) was determined from the cardiac cycles recorded on the M-mode tracing, from the echocardiography measurements. The pulsed Doppler was used to assess the isovolumetric relaxation time (IVRT), measured as the interval between aortic closure and the start of the mitral flow. 


\section{Morphological analyses of the heart and kidney}

At the end of the study, rats were weighed, and euthanized by an intraperitoneal injection of pentobarbital $(120 \mathrm{mg} / \mathrm{kg})$ and blood was collected from the left cardiac ventricle. The heart and the left kidney were carefully excised, cleaned, and weighed. The heart was also dissected into septum, left ventricle and right ventricle, which were weighted separately. Cardiac and renal weight ratios to the body weight were also determined.

\section{Biochemical analysis}

Heparinized tubes were used to collect blood. Thereafter, the blood was centrifuged at $1500 \mathrm{~g}$ for $15 \mathrm{~min}$. Plasma aliquots were prepared and kept at $-80{ }^{\circ} \mathrm{C}$ for subsequent analysis of electrolyte, urea and uric acid (Advia 20400, Siemens Healthineers).

\section{Vascular reactivity studies}

Vascular reactivity studies were performed using primary mesenteric artery rings according to the method previously described. ${ }^{30}$ Rings were contracted with $1 \mu \mathrm{M}$ of phenylephrine (PE) before the addition of increasing concentrations of acetylcholine (ACh) ranging from $0.1 \mathrm{nM}$ to $10 \mu \mathrm{M}$ to obtain concentration-response curves. In some experiments, rings were incubated with an inhibitor for 30 min before contraction with PE. In order to assess the NO-mediated component of relaxation, indomethacin $(10 \mu \mathrm{M})$, and TRAM-34 $(1 \mu \mathrm{M})$ plus apamin $(100$ $\mathrm{nM}$ ) were respectively used to inhibit cyclooxygenases and EDH-mediated relaxation, respectively whereas the EDH-mediated component of the relaxation was evaluated in the presence of indomethacin $(10 \mu \mathrm{M})$ and $\mathrm{N}^{\omega}$-nitro-L-arginine (L-NA, $300 \mu \mathrm{M}$ ) to inhibit the formation of prostanoids and NO, respectively. In endothelium intact rings, increasing concentrations of PE $(0.1 \mathrm{nM}-10 \mu \mathrm{M})$ were used to construct a concentration-contraction curve. 


\section{Immunofluorescence studies}

OCT compound (Tissue-Tek®, Sakura Finetek, Villeneuve d'Ascq, France) was used as embedding medium to snap-froze primary mesenteric artery rings in liquid nitrogen. Frozen artery rings were cryosectioned at $14 \mu \mathrm{m}$. Sections were air-dried for $15 \mathrm{~min}$ and kept in the freezer at $-80{ }^{\circ} \mathrm{C}$ until use. The slides were fixed with paraformaldehyde (4\%), washed and finally treated with $10 \%$ milk containing $0.1 \%$ Triton $\mathrm{X}-100$ for $1 \mathrm{~h}$ at room temperature in order to block non-specific binding. After an overnight at $4{ }^{\circ} \mathrm{C}$, different primary main mesentery artery sections were respectively incubated with an antibody directed against either eNOS (1:50), NADPH oxidase subunit p22 phox $(1: 50)$, cyclooxygenase-1 (COX-1, 1:250), cyclooxygenase-2 (COX-2, 1:200), or connexin 37 (Cx, 1:100). Sections were then washed with PBS, incubated with the secondary antibody (1/400, 633-conjugated goat anti-rabbit or anti mouse $\mathrm{IgG}$ ) for $2 \mathrm{~h}$ at room temperature in the dark before being washed with PBS and mounted in Dako fluorescence mounting medium (Dako, Carinteria, USA) and cover-slipped. The primary antibody was omitted for negative control. Before immunofluorescence level examination using a confocal laser-scanning microscope (Leica TSC SPE-Mannheim, Germany), samples were protected from lights. Image J software (NIH, Bethesda, Maryland, USA) was used to perform analysis of immunofluorescence signals.

\section{Determination of vascular reactive oxygen species formation}

In primary mesenteric artery rings, in situ formation of reactive oxygen species (ROS) was determined using the redox-sensitive fluorescent dye dihydroethidium (DHE). Primary mesenteric artery rings (3-4 mm length) were subsequently incorporated in OCT compound as embedding medium and snap-frozen in liquid nitrogen. Frozen arteries were cryosectioned at $25 \mu \mathrm{m}$. Sections were air-dried for $15 \mathrm{~min}$ and stored at $-80{ }^{\circ} \mathrm{C}$ until use. Dihydroethidium (2.5 $\mu \mathrm{M}$, Sigma) was applied onto unfixed cryosections of mesenteric arteries for $30 \mathrm{~min}$ at 
$37{ }^{\circ} \mathrm{C}$ in a light-protected humidified chamber, before being mounted in Dako fluorescent mounting medium and cover-slipped. Samples were kept in the dark until the fluorescence level was determined using a confocal laser-scanning microscope and analyzed using Image J.

\section{Drugs and antibodies}

DOCA was obtained from Sigma (France) and antibodies as indicated: mouse anti-eNOS (61029, BD Transduction Laboratories, East Rutherford, New Jersey, USA), COX-1 monoclonal antibody (ab109025, Abcam, Paris France), COX-2 polyclonal antibody (ab15191, Abcam, France), rabbit anti-p22 $2^{\text {phox }}$ (sc11712, Santa Cruz Biotechnology, Santa Cruz, CA, USA), connexin 37 polyclonal antibody (CX37B12-A, Alpha diagnostic international, San Antonio, Texas, USA), Alexa 633-conjugated goat anti-rabbit and antimouse IgG, (A-21070 and A-21050, respectively, Life technologies, USA).

\section{Statistical analysis}

Data are expressed as means \pm standard error of mean (SEM) of $\mathrm{n}$ experiments. Mean values were compared by ANOVA followed by the Bonferroni post-hoc test to identify significant differences between treatments, using GraphPad Prism (version 5 for Microsoft windows, GraphPad software, Inc, San Diego, CA, USA). The difference was considered to be significant when $P<0.05$.

\section{RESULTS}

Effect of AEPA treatment on DOCA-salt-induced changes of plasma electrolytes, uric acid and urea levels

The DOCA-salt administration significantly increased the plasma uric acid level and decreased the plasma level of potassium in hypertensive rats $(P<0.05$; Table 1$)$. Both AEPA 
treatments $(100$ and $300 \mathrm{mg} / \mathrm{kg} / \mathrm{d})$ normalized respectively plasma levels of uric acid and potassium in the DOCA-salt group $(P<0.05$; Table 1$)$. In addition, the plasma sodium level in the DOCA-salt group increased slightly, but not significantly compared to that of the control group (Table 1). The plasma chloride and urea levels were similar in all groups (Table 1).

Effect of AEPA treatment on DOCA-salt-induced changes on heart and kidney morphological parameters

Morphometric analysis of organs showed that except the right ventricle, the DOCA-salt treatment increased significantly the cardiac, the left ventricular, and the left kidney weight index, compared to those of the control group $(P<0.05$; Table 2). The cardiac weight index was reduced in the DOCA-salt + AEPA groups (100 or $300 \mathrm{mg} / \mathrm{kg} / \mathrm{day})$, and also that of the kidney in the DOCA-salt + AEPA (300 mg/kg/day) compared to the DOCA-salt group $(P<$ 0.05; Table 2).

\section{Intake of AEPA prevents the DOCA-salt-induced hypertension}

Following administration of DOCA-salt, SBP increased progressively and reached significantly increased levels starting at 1 week in the DOCA-salt group compared to the control group $(P<0.05$; Figure 1). Daily oral administration of AEPA (100 or 300 $\mathrm{mg} / \mathrm{kg} /$ day) significantly prevented the increase of SBP observed in DOCA-salt rats by 24 and $21 \mathrm{mmHg}$, respectively, after 5 weeks (Figure 1). The SBP of rats receiving only AEPA (100 $\mathrm{mg} / \mathrm{kg} /$ day) remained similar compared to that of the control group $(P>0.05$; Figure 1$)$. 
Intake of AEPA prevents the DOCA-salt-induced alteration of cardiac structure and

\section{function}

After 5 weeks, DOCA-salt hypertensive rats presented a left ventricular hypertrophy indicated by changes of the cardiac structure, revealed after transthoracic echocardiography, compared to those of the control group (Figure 2). A significant increase of PWT $(1.58 \pm 0.02 \mathrm{~mm}$ versus $2.24 \pm 0.05 \mathrm{~mm} ; P<0.05$; Figure $2 \mathrm{~A})$ and SWT $(1.54 \pm 0.03 \mathrm{~mm}$ versus $1.77 \pm 0.05$ $\mathrm{mm} ; P<0.05$; Figure 2B) was observed in the DOCA-salt group compared to the control group. The LVM was also significantly greater in the DOCA-salt group than the control group $(1103.61 \pm 40.13 \mathrm{mg}$ versus $755.29 \pm 24.66 \mathrm{mg} ; P<0.05$; Figure $\underline{2 \mathrm{C}})$ whereas LVEDD was not affected $(P>0.05$; Figure 2D). The AEPA treatments $(100$ and $300 \mathrm{mg} / \mathrm{kg} / \mathrm{day})$ reduced significantly the increase of PWT in the DOCA-salt groups by $0.36 \mathrm{~mm}$ and $0.30 \mathrm{~mm}$, respectively, SWT by $0.18 \mathrm{~mm}$ and $0.17 \mathrm{~mm}$, respectively and LVM by $268.55 \mathrm{mg}$ and $251.61 \mathrm{mg}$, respectively $(P<0.05$; Figures $2 \mathrm{~A}-\mathrm{C})$. Parameters for the AEPA group (100 $\mathrm{mg} / \mathrm{kg} /$ day) were similar to those of the control group $(P>0.05$; Figure 2$)$.

Analyses of the cardiac function indicated that, IVRT was significantly increased in the DOCA-salt group compared to that of the control group (45.71 \pm 1.96 ms versus $35.5 \pm 2.83$ ms respectively; $P<0.05$; Figure $2 \mathrm{E}$ ). The AEPA treatments $(100$ and $300 \mathrm{mg} / \mathrm{kg} / \mathrm{day})$ improved IVRT in DOCA-salt treated rats with values close to normal, $36.67 \pm 3.47$ and $36.88 \pm 2.37 \mathrm{~ms}$, respectively $(P<0.05$; Figure $2 \mathrm{E})$. In contrast, the AEPA $(100 \mathrm{mg} / \mathrm{kg} / \mathrm{day})$ alone did not affect IVRT (Figure 2E). The LVEF was slightly decreased in DOCA-salt rats compared to that of the control group, but this effect did not reach statistical significance $(P>$ 0.05; Figure $2 \mathrm{~F}$ ). In addition, $\mathrm{CO}$ and $\mathrm{HR}$ were slightly and not significantly decreased in the DOCA-salt group compared with the control group, and not affected by the AEPA treatments (100 and $300 \mathrm{mg} / \mathrm{kg} /$ day; $P>0.05$; Figures $2 \mathrm{G}, \mathrm{H})$. 
Intake of AEPA improves the DOCA-salt-induced endothelial dysfunction in the primary mesenteric artery: role of NO and EDH

The DOCA-salt treatment increased significantly phenylephrine-induced vasoconstriction in primary mesenteric artery rings with endothelium compared to the control group $(P<0.05$; Figure 3A). Intake of AEPA (300 mg/kg/day) normalized the phenylephrine inducedcontractile response in the DOCA-salt group, whereas $100 \mathrm{mg} / \mathrm{kg} / \mathrm{day}$ was without effect (Figure 3A).

The DOCA-salt group presented an endothelial dysfunction as indicated by a significantly reduced acetylcholine induced endothelium-dependent relaxation compared to that of the control group $(P<0.05$; Figure 3B). Treatment with AEPA (100 or $300 \mathrm{mg} / \mathrm{kg} /$ day) improved the DOCA-salt-induced endothelial dysfunction to acetylcholine $(P<0.05$; Figure 3B).

In primary mesenteric artery rings with endothelium, both the NO-mediated (assessed in the presence of indomethacin and Tram-34 plus apamin) and the endothelium-dependent hyperpolarization $(\mathrm{EDH})$-mediated (assessed in the presence of indomethacin and $\mathrm{N}^{\omega}$-nitro-Larginine) relaxations to acetylcholine were significantly reduced in the DOCA-salt group compared to those of the control group $(P<0.05$; Figures 4A,B). Treatment with AEPA (100 or $300 \mathrm{mg} / \mathrm{kg} /$ day) improved the DOCA-salt-induced blunted NO- and EDH-mediated relaxations in the primary mesenteric artery (Figures 4A,B).

\section{AEPA prevents the DOCA-salt-induced increased primary mesenteric artery oxidative stress and up-regulation of NADPH oxidase subunit p22 ${ }^{\text {phox }}$}

Immunofluorescence studies showed that the DOCA-salt treatment was associated with oxidative stress throughout the primary mesenteric artery wall as shown by an increased DHE fluorescence signal, which amounted to $124.17 \pm 4.89 \%(P<0.05$; Figure 5A). Moreover, the increased level of oxidative stress in primary mesenteric artery induced by DOCA-salt 
was associated with a significant increased expression of the NADPH oxidase subunits $\mathrm{p} 22^{\text {phox }}$ in the arterial wall, amounted to about $198.82 \pm 17.17 \%$ in the DOCA-salt group $(P<$ 0.05; Figure 5B). Both AEPA treatments prevented the DOCA-salt-induced increased vascular oxidative stress and up-regulation of NADPH oxidase $(P<0.05$; Figures 5A,B).

AEPA prevents the DOCA-salt-induced increased expression of eNOS and decreased expression of connexin 37 in the primary mesenteric artery

Immunofluorescence staining indicated a significant increased expression of eNOS (188.22 \pm $12.91 \% ; P<0.05$; Figure 5C) and a decreased expression of connexin Cx37 (32.39 $\pm 3.23 \%$; $P<0.05$; Figure 5D) in the primary mesenteric artery of the DOCA-salt group compared to those of the control group. Both AEPA treatments prevented the deleterious effect of the DOCA-salt treatment on the expression of eNOS, and also the AEPA (100 mg/kg/day) treatment on the expression of $\mathrm{Cx} 37(P<0.05$; Figures 5C,D).

AEPA prevents the DOCA-salt-induced increased expression of COX-2, but not COX-1 in the primary mesenteric artery

The immunofluorescence COX-2 signal was significantly increased in the primary mesenteric artery of the DOCA-salt group, which amounted to $153.72 \pm 12.44 \%$; $(P<0.05$; Figure 5F). After AEPA treatment, a significant reduction of the COX-2 immunofluorescence level was observed in the DOCA + AEPA (100 and $300 \mathrm{mg} / \mathrm{kg} / \mathrm{day})$ groups $(P<0.05$; Figure 5F). Also, the expression level of COX-2 was slightly reduced in AEPA (100 mg/kg/day) group compared to that of the control group, however this effect did not reach statistical significance $(P>0.05$; Figure 5F). In contrast to the COX-2 signal, the expression level of COX-1 was similar in the different groups $(P>0.05$; Figure 5E). 


\section{DISCUSSION}

The major findings indicate that daily oral intake of an aqueous extract of Phyllantus amarus for 5 weeks prevented effectively the hypertensive response observed after the subcutaneously injection of deoxycorticosterone acetate (DOCA) and intake of $1 \% \mathrm{NaCl}$ in rats. The preventive beneficial effect of the AEPA is related to an improved cardiac structure and function, and also with an improved endothelial dysfunction affecting both the NO and EDH components.

Consistent with previous studies, DOCA-salt induced a progressive hypertensive response in rats, which reached a plateau phase after about 4 weeks, and is associated with the development of cardiac hypertrophy, especially in the left ventricle. ${ }^{5,9,7}$ The transthoracic echocardiography analysis of DOCA-salt rats has indicated an increase of both PWT and SWT associated with an increase of LVM without dilation of the left ventricular chamber, indicating a concentric type of hypertrophy. ${ }^{31}$ In addition, analysis of the cardiac function showed an impairment of diastolic function in DOCA-salt rats, as confirmed by an increase of IVRT. The ejection fraction (LVEF) was slightly reduced in the DOCA-salt group, but the value remained within the normal range i.e. greater than $50 \% .^{32}$. Moreover, abnormal heart function observed in DOCA-salt rats is associated with minor changes of cardiac output and heart rate. Altogether, these findings are in good agreement with previous ones indicating that at early stages of hypertension, the cardiac diastolic function is impaired before the systolic function. ${ }^{33}$ The present findings reveal that daily oral intake of AEPA was able to significantly prevent the hypertensive response to DOCA-salt, with a cardioprotective action including an antihypertrophic effect with improved PWT, SWT and LVM values, and an improved diastolic cardiac function with normal IVRT. Thus, these findings provide experimental evidence of the antihypertensive potential of Phyllantus amarus as well as its ability to prevent consequences of hypertension at the heart function and structure in chronic 
situation. A previous study has also reported that oral intake of an extract of Moringa oleifera (Moringaceae) seeds decreased the LVM and improved the diastolic function in the SHR, associated with an up-regulation of peroxisome proliferator-activated receptor (PPAR)- $\alpha$ and $\delta$ signaling, which play a crucial role in fatty acid catabolism in the heart. ${ }^{34}$ Moreover, Euterpe oleracea (Arecaceae) prevented cardiac disorders such as hypertrophy and fibrosis in rats after myocardial infarction. ${ }^{14}$

Besides the heart, chronic hypertension is known to cause damage to several end organs and, in particular, the kidney affecting its function and structure. ${ }^{35,36}$ The present findings indicate that DOCA-salt hypertension is associated with an increased left kidney weight and plasma uric acid level, and a reduced plasma potassium level. Moreover since chronic hypokalemia has been involved in cardiac hypertrophy when hypertension is associated with primary aldosteronism, ${ }^{8,37,38}$ the ability of the AEPA treatment to normalize the plasma potassium level might contribute to explain, at least in part, the improved kidney function and structure in the AEPA-treated DOCA-salt group. An improved kidney function and structure has also been observed with sesame oil and quercetin in the DOCA-salt hypertensive rat. ${ }^{5,8}$

Endothelial dysfunction is an early common arterial deleterious effect appearing before structural changes of the arterial wall in experimental models of hypertension, and also in hypertensive humans. ${ }^{10,39}$ In the DOCA-salt hypertensive group, the endothelial dysfunction of the main mesenteric artery is characterized by blunted endothelium-dependent relaxations to acetylcholine, and also the appearance of an exaggerated contractile response to phenylephrine. Moreover, the characterization of the endothelial dysfunction to acetylcholine indicated that both the NO and EDH components were significantly reduced in the primary mesenteric artery of the DOCA-salt group. Interestingly, the AEPA treatment at both 100 and $300 \mathrm{mg} / \mathrm{kg} /$ day prevented the DOCA-salt-induced endothelial dysfunction as indicated by normal NO and EDH components in response to acetylcholine, and also at $300 \mathrm{mg} / \mathrm{kg} / \mathrm{day}$ a 
normal contractile response to phenylephrine was observed. In addition, the Phyllanthus amarus aqueous extract induced pronounced concentration-dependent relaxations in coronary artery rings solely in the presence of a functional endothelium (unpublished data).

The AEPA treatments at 100 and $300 \mathrm{mg} / \mathrm{kg} /$ day protected the cardiovascular system of DOCA-salt hypertensive rats to a similar extent. Such effect, is possibly due to the fact that the antihypertensive effect of AEPA reached already a maximal response at a dose of 100 $\mathrm{mg} / \mathrm{kg} / \mathrm{day}$. In addition, according to a previous study, the observed AEPA-induced hypotensive effects in rabbits was characterized by an $\mathrm{ED}_{50}$ of $25.77 \mathrm{mg} / \mathrm{kg} .{ }^{23}$.

Besides Phyllantus amarus, several other types of natural products such as a red wine polyphenols extract, an ethanolic extract of Lindera obtusiloba or the sesame lignan sesamin have been shown to prevent endothelial dysfunction in several experimental models of hypertension including the DOCA-salt model, in part, by preventing vascular oxidative stress. ${ }^{30,40-44}$ Indeed, an increased level of oxidative stress is observed throughout the arterial wall of hypertensive arteries subsequent to the up-regulation of the expression of NADPH oxidase ${ }^{45,46}$ and it has been shown to promote uncoupling of endothelial NO synthase most likely triggered by oxidation of the essential eNOS cofactor tetrahydrobiopterin, ${ }^{30,47}$ alteration of calcium-dependent $\mathrm{K}^{+}$channels and connexins such as $\mathrm{Cx} 37$ involved in $\mathrm{EDH},{ }^{12,48,49}$ and an increased expression of cyclooxygenases involved in endothelium-dependent contractile responses. ${ }^{50,51}$ The present findings indicate that the AEPA treatment was able to effectively prevent the DOCA-salt-induced oxidative stress and the up-regulation of the NADPH oxidase subunit $\mathrm{p} 22^{\text {phox }}$ in the primary mesenteric artery wall. They further indicate that the AEPA treatment prevented the DOCA-salt-induced up-regulation of eNOS expression most likely part of a compensatory mechanism subsequent of an enhanced degradation of NO by superoxide anions, and also partially the down-regulation of Cx37. Moreover, the AEPA treatment prevented the up-regulation of $\mathrm{COX}-2$, a redox-sensitive NF-kB-controlled pro- 
inflammatory enzyme, in the primary mesenteric artery of the DOCA-salt group. Such an effect is in good agreement with previous in vivo and in vitro findings indicating that Phyllanthus species such as Phyllanthus amarus and Phyllanthus acidus reduced inflammatory responses by preventing COX-2 overexpression in RAW 264.7 cells, ${ }^{18,51}$ and the high-fructose diet-induced cardiac oxidative stress in rats. ${ }^{53}$ Moreover, Phyllanthus amarus hexane and hydroalcoholic extracts induced a potent anti-inflammatory effect in RAW 264.7 macrophages by preventing the expression of iNOS, COX-2, and proinflammatory cytokines such as IL- $1 \beta$ and IFN- $\gamma$, in response to activation of NF-kB. ${ }^{18}$

Moreover, lignans, hydrolysable tannins, flavonoids, alkaloids, triterpenes, sterols and volatile oils are known as main secondary metabolites present in Phyllanthus amarus. ${ }^{54,55}$ According to our previous study, the phytochemical analysis of the aqueous extract of whole plant of Phyllanthus amarus has revealed the presence of alkaloids, polyphenols, terpenes and sterols. ${ }^{23}$ Although the contribution of these different classes of natural products to the beneficial effect of Phyllanthus amarus on DOCA-salt-induced hypertension, cardiac hypertrophy and dysfunction, and endothelial dysfunction in rats remains to be determined, it is possibly related to the combined action of these secondary metabolites, acting in a synergistic manner.

Altogether, the findings indicate that AEPA has antihypertensive properties, and prevents endothelial dysfunction, and cardiac hypertrophy and dysfunction in DOCA-salt hypertensive rats. Furthermore, the protective vascular effect of the AEPA treatment is associated with an improvement of both the NO and EDH components and also of the expression of major target proteins involved in these pathways including eNOS and Cx37, in part, by reducing the level of vascular oxidative stress. 


\section{ACKNOWLEDGMENTS}

Authors are thankful to Brigitte Pollet (Faculté de Pharmacie, Université de Strasbourg) and Professor Jean Marc Lessinger (Nouvel Hôpital Civil, Strasbourg) for technical assistance, respectively in vascular reactivity studies and biochemical analysis.

\section{REFERENCES}

1. WHO (World health organization). A global brief on hypertension: silent killer, global public health crisis [WHO web site]. April, 2013. Available at: https://www.who.int/

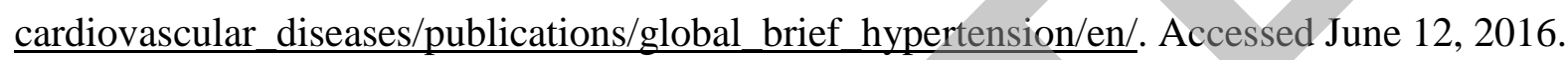

2. Kannel WB. Risk stratification in hypertensive: New insights from the Framinghan study. Am J Hypertens. 2000; 13: 3S-10S.

3. Tsotetsi OJ, Woodiwiss AJ, Netjhard M, Qubu D, Brooksbank R, Norton GR. Attenuation of cardiac failture, dilatation, damage, and detrimental interstitial remodeling without regression of hypertrophy in hypertensive rats. Hypertension. 2001; 38: 846-851.

4. D’Agostino RBSr, Vasan RS, Pencina MJ, Wolf PA, Cobain M, Massaro JM, Kannel WB. General cardiovascular risk profile for use in primary care: the Framingham heart study. Circulation. 2008; 117:743-753.

5. Galisteo M, García-Saura MF, Jiménez R, Villar IC, Wangensteen R, Zarzuelo A, Vargas F, Duarte J. Effects of quercetin treatment on vascular function in deoxycorticosterone acetate-salt hypertensive rats. Comparative study with verapamil. Planta Med. 2004; 70: 334341.

6. Wilcox CS, Pearlman A. Chemistry and antihypertensive effects of tempol and other nitroxides. Pharmacol Rev. 2008; 60: 418-469.

7. Iyer A, Chan V, Brown L. The DOCA-salt hypertensive rat as a model of cardiovascular oxidative and inflammatory stress. Curr Cardiol Rev. 2010; 6: 291-297. 
8. Liu CT, Periasam S, Chang CC, Mo FE, Liu MY. Sesame oil therapeutically ameliorates cardiac hypertrophy by regulating hypokalemia in hypertensive rats. $J$ Parenter Enteral Nutr. 2014; 38: 750-757.

9. Fenning A, Harrison G, Rose'meyer R, Hoey A, Brown L. L- Arginine attenuates cardiovascular impairement in DOCA-salt hypertensive rats. Am J Physiol Heart Circ Physiol. 2005; 289:H1408-H1416.

10. Perez-Vizcaino F, Duare J, Jimenez R, Santos-Buelga C, Osuna A. Antihypertensive effects of the flavonoid quercetin. Pharmacol Rep. 2009; 61: 67-75.

11. Li Z, Wang Y, Man RYK, Vanhoutte PM. Upregulation of heme oxygenase-1 potentiates EDH-type relaxations in the mesenteric artery of the spontaneously hypertensive rat. Am $J$ Physiol Heart Circ Physiol. 2013; 305: H1471-H1483.

12. Rashid SK, Khodja NI, Auger C, Alhosin M, Boehm N, Oswald-Mammosser M, SchiniKerth VB. Probiotics (VSL\#3) prevent endothelial dysfunction in rats with portal hypertension: role of the angiotensin system. PLoSOne. 2014; 9: e97458.

13. O'Brien D, Chunduri P, Iyer A, Brown L. L-Carnitine attenuates cardiac remodelling rather than vascular remodelling in deoxycorticosterone acetate-salt hypertensive rats. Basic Clin Pharmacol Toxicol. 2010;106 : 296-301.

14. Zapata-Sudo G, Silva JS, Pereira SL, Souza PJC, Moura RS, Sudo RT. Oral treatment with Euterpe oleracea Mart. (açaí) extract improves cardiac dysfunction and exercise intolerance in rats subjected to myocardial infarction. BMC Complement Altern Med. 2014; 14: 227.

15. Tra-Bi FH, Irié GM, N'gaman KC, Mohou CHB. Etude de quelques plantes thérapeutiques utilisées dans le traitement de l'hypertension artérielle et du diabète: deux maladies émergentes en Côte d'Ivoire. Sci Nat. 2008; 5 :39-48. 
16. N'guessan K, Tiébré MS, Aké-Assi E, Zirihi GN. Ethnobotanical study of plants used to treat arterial hypertension, in traditional medicine, by Abbey and Krobou populations of Agboville (Côte d'Ivoire). Eur J Sci Res. 2009a; 35 : 85-98.

17. N'guessan K, Kadja B, Zihiri GN. Traoré D, Aké-Assi L. Screening phytochimique de quelques plantes médicinales utilisées en pays krobou (Agboville, Côte-d'Ivoire). Sci Nat. 2009b; 6: 1-5.

18. Kiemer AK, Hartung T, Huber C, Vollmar AM. Phyllanthus amarus induced a potent anti-inflammatory effect resulting by inhibition of iNOS, COX-2, and cytokines via the NFkB pathway. J Hepatol. 2003; 38: 289-297.

19. Roengrit T, Wannanon P, Prasertsri P, Kanpetta Y, Sripanidkulchai B, Leelayuwat N. Antioxidant and anti-nociceptive effects of Phyllanthus amarus on improving exercise recovery in sedentary men: a randomized crossover (double-blind) design. J Int Soc Sports Nutr. 2014; 11: 9.

20. Srividya N, Periwal S. Diuretic, hypotensive and hypoglycemia effect of Phyllanthus amarus. Indian J Exp Biol 1995; 33: 861- 864.

21. Amaechina FC, Omogbai EK. Hypotensive effect of aqueous extract of the leaves of Phyllanthus amarus Schum and Thonn (Euphorbiaceae). Acta Pol Pharm. 2007; 64: 547-542.

22. Inchoo M, Chirdchupunseree H, Pramyothin P, Jianmongkol S. Endothelium-independent effects of phyllanthin and hypophyllanthin on vascular tension. Fitoterapia. 2011; 82: 12311236.

23. Amonkan AK, Kamagaté M, Yao ANR, Konan AB, Kouamé, MN, Koffi C, KatiCoulibaly S, Die-Kakou H. Comparative effects of two fractions of Phyllanthus amarus (Euphorbiaceae) on the blood pressure in rabbit. Greener J Med Sci. 2013; 3: 129-134.

24. Yao AN, Kamagaté M, Amonkan AK, Chabert P, Kpahé F, Koffi C, Kouamé MN, Auger C, Kati-Coulibaly S, Schini-Kerth V, Die-Kakou H. The acute diuretic effect of an ethanolic 
fraction of Phyllanthus amarus (Euphorbiaceae) in rats involves prostaglandins. BMC Complement Altern. Med. 2018; 18: 94.

25. Yao AN, Kamagaté M, Amonkan AK, Koffi C, Kpahé F, Kouamé MN, Dié-Kacou H. Comparative effects of aqueuos extract of Phyllanthus amarus and its fractions on urinary excretion in rat. J Phytopharmacol. 2016; 5:182-184.

26. Putakala M, Gujjala S, Nukala S, Bongu SBR, Chintakunta N, Desireddy S. Cardioprotective effect of Phyllanthus amarus against high fructose diet induced myocardial and aortic stress in rat model. Biomed Pharmacother. 2017; 95: 1359-1368.

27. Margulies RL. Protecting biodiversity: recognizing international intellectual property rights in plant genetic resources. Mich J Int'lL. 1993; 14: 322.

28. Utkarsh G, Gadgil M, Rao PRS. Intellectual property rights on biological resources: benefiting from biodiversity and people's knowledge. Curr Sci. 1999; 77: 1418-1425.

29. NIH (National Institutes of Health). Guide for the care and use of laboratory animals.

[NIH web site]. August 16, 1996. Available at: https://grants.nih.gov/grants/olaw/Guide-forthe-Care-and-use-of-laboratory-animals.pdf. Accessed January 21, 2016.

30. Lee JO, Auger C, Park DH, Kang M, Oak MH, Kim KR, Schini-Kerth VB. An ethanolic extract of Lindera obtusiloba Stems, YJP-14, improves endothelial dysfunction, metabolic parameters and physical performance in diabetic db/db mice. PLoS One. 2013; 8: e65227.

31. Chan V, Hoey A, Brown L. Improved cardiovascular function with aminoguanidine in DOCA-salt hypertensive rats. Br J Pharmacol. 2006; 148: 902-908.

32. Kawaguchi M, Hay I, Fetics B, Kass DA. Combined ventricular systolic and arterial stiffening in patients with heart failure and preserved ejection fraction. Implications for systolic and diastolic reserve limitations. Circulation. 2003; 107:714-20.

33. Ayme-Dietrich E, Marzak H, Lawson R, Mokni W, Wendling O, Combe R, Becker J, Fertak LE, Champy MF, Matz R, Andriantsitohaina R, Doly S, Boutourlinsky K, Maroteaux 
L, Monassier L. Contribution of serotonin to cardiac remodeling with hypertensive diastolic ventricular dysfunction in rats. J Hypertens. 2015; 33 : 2310-2321.

34. Randriamboavonjy JI, Loirand G, Vaillant N, Lauzier B, Derbre S, Michalet S, Pacaud P, Tesse A. Cardiac protective effects of Moringa oleifera seeds in spontaneous hypertensive rats. Am J Hypertens. 2016; 29: 873-881.

35. Manning RDJr, Tian N, Meng S. Oxidative stress and antioxidant treatment in hypertension and the associated renal damage. Am J Nephrol. 2005; 25:311-317.

36. Cha RH, Kim S, Ae Yoon S, Ryu DR, Eun Oh J, Han SY, Young Lee E, Ki Kim D, Kim YS. Association between blood pressure and target organ damage in patients with chronic kidney disease and hypertension: results of the APrODiTe study. Hypertens Res. 2014; 37: $172-178$

37. Wang Q, Domenighetti AA, Pedrazzini T, Burnier M. Potassium supplementation reduces cardiac and renal hypertrophy independent of blood pressure in DOCA/salt mice. Hypertension. 2005; 46: 547-454.

38. Kato Y, Kurisu S, Mitsuba N, Ishibashi K, Dohi Y, Nishioka K, Kihara Y. Effects of hypokalemia and left ventricular hypertrophy on QT interval in patients with primary aldosteronism. Int J Cardiol. 2011; 152: 380-381.

39. Virdis A, Taddei S. Endothelial dysfunction in resistance arteries of hypertensive humans: old and new conspirators. J Cardiovasc Pharmacol. 2016; 67: 451-457.

40. Sarr M, Chataigneau M, Martins S, Schott C, El Bedoui J, Oak MH, Muller B, Chataigneau T, Schini-Kerth VB. Red wine polyphenols prevent angiotensin II-induced hypertension and endothelial dysfunction in rats: role of NADPH oxidase. Cardiovasc Res. $2006 ; 71: 794-802$.

41. Jiménez R, López-Sepúlveda R, Kadmiri M, Romero M, Vera R, Sánchez M, Vargas F, O'Valle F, Zarzuelo A, Dueñas M, Santos-Buelga C, Duarte J. Polyphenols restore endothelial 
function in DOCA-salt hypertension: Role of endothelin-1 and NADPH oxidase. Free Radic Biol Med. 2007; 43: 462-473.

42. Nakano D, Kurumazuka D, Nagai Y, Nishiyama A, Kiso Y, Matsumura Y. Dietary sesamin suppresses aortic NADPH oxidase in DOCA-salthypertensive rats. Clin Exp Pharmacol Physiol. 2008; 35: 324-326.

43. Dal-Ros S, Bronner C, Schott C, Kane MO, Chataigneau M, Schini-Kerth VB, Chataigneau, T. Angiotensin II-induced hypertension is associated with a selective inhibition of endothelium-derived hyperpolarizing factor-mediated responses in the rat mesenteric artery. J Pharmacol Exp Ther. 2009; 328: 478-486.

44. Kane MO, Etienne-Selloum N, Madeira SV, Sarr M, Walter A, Dal-Ros S, Schott C, Chataigneau T, Schini-Kerth VB. Endothelium-derived contracting factors mediate the Ang II-induced endothelial dysfunction in the rat aorta: preventive effect of red wine polyphenols. Pflugers Arch. 2010 ; 459: 671-679.

45. Harrison DG, Cai H, Landmesser U, Griendling KK. Interactions of angiotensin II with NAD(P)H oxidase, oxidant stress and cardiovascular disease. $J$ Renin Angiotensin Aldosterone Syst. 2003; 4: 51-61.

46. Sunggip C, Kitajima N, Nishida M. Redox control of cardiovascular homeostasis by angiotensin II. Curr. Pharm Des. 2013; 19: 3022-3032.

47. Landmesser U, Dikalov S, Price SR, McCann L, Fukai T, Holland SM, Mitch WE, Harrison DG. Oxidation of tetrahydrobiopterin leads to uncoupling of endothelial cell nitric oxide synthase in hypertension. J Clin Invest. 2003; 11: 1201-1209.

48. de Wit C, Griffith MT. Connexins and gap junctions in the EDHF phenomenon and conducted vasomotor responses. Pflugers Arch. 2010; 459: 897-914. 
49. Behringer EJ, Shaw RL, Westcott EB, Socha MJ, Segal SS. Aging impairs electrical conduction along endothelium of resistance arteries through enhanced $\mathrm{Ca} 2+$-activated $\mathrm{K}+$ channel activation. Arterioscler Thromb Vasc Biol. 2013; 33: 1892-1901.

50. Ohnaka K, Numaguchi K, Yamakawa T, Inagami T. Induction of cyclooxygenase-2 by angiotensin II in cultured rat vascular smooth muscle cells. Hypertension. 2000; 35: 68-75.

51. Félétou M, Huang Y, Vanhoutte PM. Endothelium-mediated control of vascular tone: COX-1 and COX-2 products. Br J Pharmacol. 2011; 164: 894-912.

52. Hossen MJ, Jeon SH, Kim SC, Kim JH, Jeong D, Sung NY, Yang S, Baek KS, Kim JH, Yoon DH, Song WO, Yoon KD, Cho SH, Lee S, Kim JH, Cho JY,. In vitro and in vivo antiinflammatory activity of Phyllanthus acidus methanolic extract. J Ethnopharmacol. 2015; 168: $217-228$.

53. Kuttan R, Harikumar KB. Phyllanthus species. Scientific evaluation and medicinal applications. Boca Raton: CRC Press, 2012.

54. Patel JR, Tripathi P, Sharma V, Chauhan NS, Dixit VK. Phyllanthus amarus: ethnomedicinal uses, phytochemistry and pharmacology: a review. J Ethnopharmacol. 2011; 138: $286-313$. 


\section{Figure legends}

Figure 1: Effect of AEPA treatment on systolic blood pressure (SBP) measured by tail-cuff sphygmomanometry. Results are shown as mean \pm SEM of 7 to 8 different rats. ${ }^{*} P<$ 0.05 versus the control group; ${ }^{\#} P<0.05$ versus the DOCA-salt group.

Figure 2: Effect of AEPA treatment on left ventricle cardiac hypertrophy and function. (A) PWT: posterior diastolic wall thickness, (B) SWT: septum diastolic wall thickness, (C) LVM: left ventricular mass, (D) LVEDD: left ventricle end-diastolic diameter, (E) IVRT: isovolumetric relaxation time, $(\mathrm{F})$ LVEF: left ventricle ejection fraction, $(\mathrm{G})$ CO: cardiac output, and $(\mathrm{H}) \mathrm{HR}$ : heart rate. Results are shown as mean \pm SEM of 7 to 8 different rats. ${ }^{*} P<0.05$ versus the control group; ${ }^{\#} P<0.05$ versus the DOCA-salt group.

Figure 3: AEPA treatment prevents endothelial dysfunction induced by DOCA-salt in rats. (A) Arterial rings from the primary mesenteric artery with endothelium were subjected to increasing concentrations of phenylephrine to construct concentrationcontraction curves. (B) Arterial rings from the primary mesenteric artery with endothelium were precontracted with $10^{-6} \mathrm{M}$ of phenylephrine before the addition of increasing concentrations of acetylcholine to construct concentration-relaxation curyes. Results are shown as mean \pm SEM of $4-5$ rats per group. ${ }^{*} P<0.05$ versus the control group; ${ }^{\#} P<0.05$ versus the DOCA-salt group.

Figure 4: Improvement of both the NO and EDH components of the endothelium-dependent relaxation to acetylcholine by the AEPA treatment in DOCA-salt hypertensive rats. Arterial rings from the primary mesenteric artery with endothelium were precontracted 
with $10^{-6} \mathrm{M}$ of phenylephrine before the addition of increasing concentrations of acetylcholine to construct concentration-relaxation curves. (A) Nitric oxide (NO)mediated relaxations were obtained in presence of indomethacin $(10 \mu \mathrm{M}$, to prevent the formation of vasoactive prostanoids), and charybdotoxin $(100 \mathrm{nM})$ plus apamin (100 nM; two inhibitors of EDH-mediated relaxations) for 30 min before construction of the concentration-response curve. (B) Endothelium-dependent hyperpolarization (EDH)-mediated relaxations were obtained in the presence of indomethacin $(10 \mu \mathrm{M})$ to prevent the formation of vasoactive prostanoids, and $\mathrm{N}^{\mathrm{G}}$-nitro-L-arginine $(100 \mu \mathrm{M}$, an inhibitor of endothelial NO synthase) for $30 \mathrm{~min}$ before construction of the concentration-response curve. Results are shown as mean \pm SEM of 4-5 rats per group. ${ }^{*} P<0.05$ versus the control group; ${ }^{\#} P<0.05$ versus the DOCA-salt group.

Figure 5: Effect of AEPA treatment on the DOCA-salt-induced changes in vascular oxidative stress, and markers of NO, EDH and cyclooxygenase pathways. (A) The level of oxidative stress (in situ ROS formation) was determined in primary mesenteric artery sections by fluorescence histochemistry using the redox-sensitive probe dihydroethidium. The expression level of (B) NADPH oxidase subunit $\mathrm{p} 22^{\text {phox }},(\mathrm{C})$ eNOS, (D) connexin 37, (E) COX-1 and (F) COX-2 was assessed in mesenteric artery sections by immunofluorescence. Sections were observed using a confocal laser-scanning microscope. Values are shown as mean \pm SEM of 4-5 rats per group. ${ }^{*} P<0.05$ versus the control group; ${ }^{\#} P<0.05$ versus the DOCA-salt group. 
Table 1: Effect of AEPA treatment on biochemical parameters in the control and DOCA-salt hypertensive group of rats.

\begin{tabular}{|l|c|c|c|c|c|}
\hline Groups & Control & $\begin{array}{c}\text { AEPA } \\
(100 \mathrm{mg} / \mathrm{kg} / \mathrm{d})\end{array}$ & DOCA & $\begin{array}{c}\text { DOCA + AEPA } \\
(100 \mathrm{mg} / \mathrm{kg} / \mathrm{d})\end{array}$ & $\begin{array}{c}\text { DOCA + AEPA } \\
(300 \mathrm{mg} / \mathrm{kg} / \mathrm{d})\end{array}$ \\
\hline Urea $(\mathrm{g} / \mathrm{l})$ & $0.29 \pm 0.01$ & $0.28 \pm 0.02$ & $0.30 \pm 0.04$ & $0.31 \pm 0.01$ & $0.32 \pm 0.02$ \\
\hline Uric acid $(\mathrm{mg} / \mathrm{l})$ & $7.00 \pm 1.00$ & $6.66 \pm 0.68$ & $11.25 \pm 0.48^{*}$ & $6.67 \pm 0.52^{\#}$ & $8.00 \pm 0.50^{\#}$ \\
\hline Sodium $(\mathrm{mmol} / \mathrm{l})$ & $143.20 \pm 1.11$ & $144.4 \pm 1.03$ & $147.50 \pm 0.65$ & $147.8 \pm 0.66$ & $146.75 \pm 0.75$ \\
\hline Potassium $(\mathrm{mmol} / \mathrm{l})$ & $5.54 \pm 0.2$ & $5.07 \pm 0.10$ & $4.18 \pm 0.08^{*}$ & $5.26 \pm 0.34^{\#}$ & $5.14 \pm 0.39^{\#}$ \\
\hline Chloride $(\mathrm{mmol} / \mathrm{l})$ & $99.00 \pm 1.08$ & $101.20 \pm 1.52$ & $100.00 \pm 3.63$ & $99.00 \pm 2.35$ & $102.5 \pm 0.29$ \\
\hline
\end{tabular}

Results are shown as mean \pm SEM of 4 to 5 different rats. ${ }^{*} P<0.05$ versus control group and ${ }^{\#} P<0.05$ versus DOCA-salt group. 
Table 2: Effect of AEPA treatment on physiological parameters in the control and DOCAsalt hypertensive group of rats.

\begin{tabular}{|l|c|c|c|c|c|}
\hline Groups & Control & $\begin{array}{c}\text { AEPA } \\
(100 \mathrm{mg} / \mathrm{kg} / \mathrm{d})\end{array}$ & DOCA & $\begin{array}{c}\text { DOCA + AEPA } \\
(100 \mathrm{mg} / \mathrm{kg} / \mathrm{d})\end{array}$ & $\begin{array}{c}\text { DOCA + AEPA } \\
(300 \mathrm{mg} / \mathrm{kg} / \mathrm{d})\end{array}$ \\
\hline BW $(\mathrm{g})$ & $401.43 \pm 11.55$ & $407.83 \pm 8.38$ & $397.14 \pm 10.32$ & $402.50 \pm 19.11$ & $413.42 \pm 7.11$ \\
\hline HW/BW $(\mathrm{mg} / \mathrm{g})$ & $2.73 \pm 0.08$ & $2.60 \pm 0.05$ & $3.40 \pm 0.23^{*}$ & $2.75 \pm 0.01^{\#}$ & $2.73 \pm 0.01^{\#}$ \\
\hline LVW/ BW (mg/g) & $1.04 \pm 0.05$ & $0.98 \pm 0.03$ & $1.34 \pm 0.11^{*}$ & $1.15 \pm 0.04$ & $1.08 \pm 0.05^{\#}$ \\
\hline RVW/BW (mg/g) & $0.46 \pm 0.02$ & $0.45 \pm 0.03$ & $0.58 \pm 0.04$ & $0.53 \pm 0.03$ & $0.47 \pm 0.02$ \\
\hline LKW/BW (mg/g) & $3.18 \pm 0.12$ & $2.81 \pm 0.06$ & $3.71 \pm 0.18^{*}$ & $3.21 \pm 0.12$ & $3.09 \pm 0.08^{\#}$ \\
\hline
\end{tabular}

BW, body weight; HW/BW, cardiac weight index, LVW/ BW, left ventricle weight index; RVW/BW, right ventricle weight index; LKW/BW, left kidney weight index. Results are shown as mean \pm SEM of 7 to 8 different rats. ${ }^{*} P<0.05$ versus control group and ${ }^{\#} P<0.05$ versus DOCA-salt group. 
Figure 1

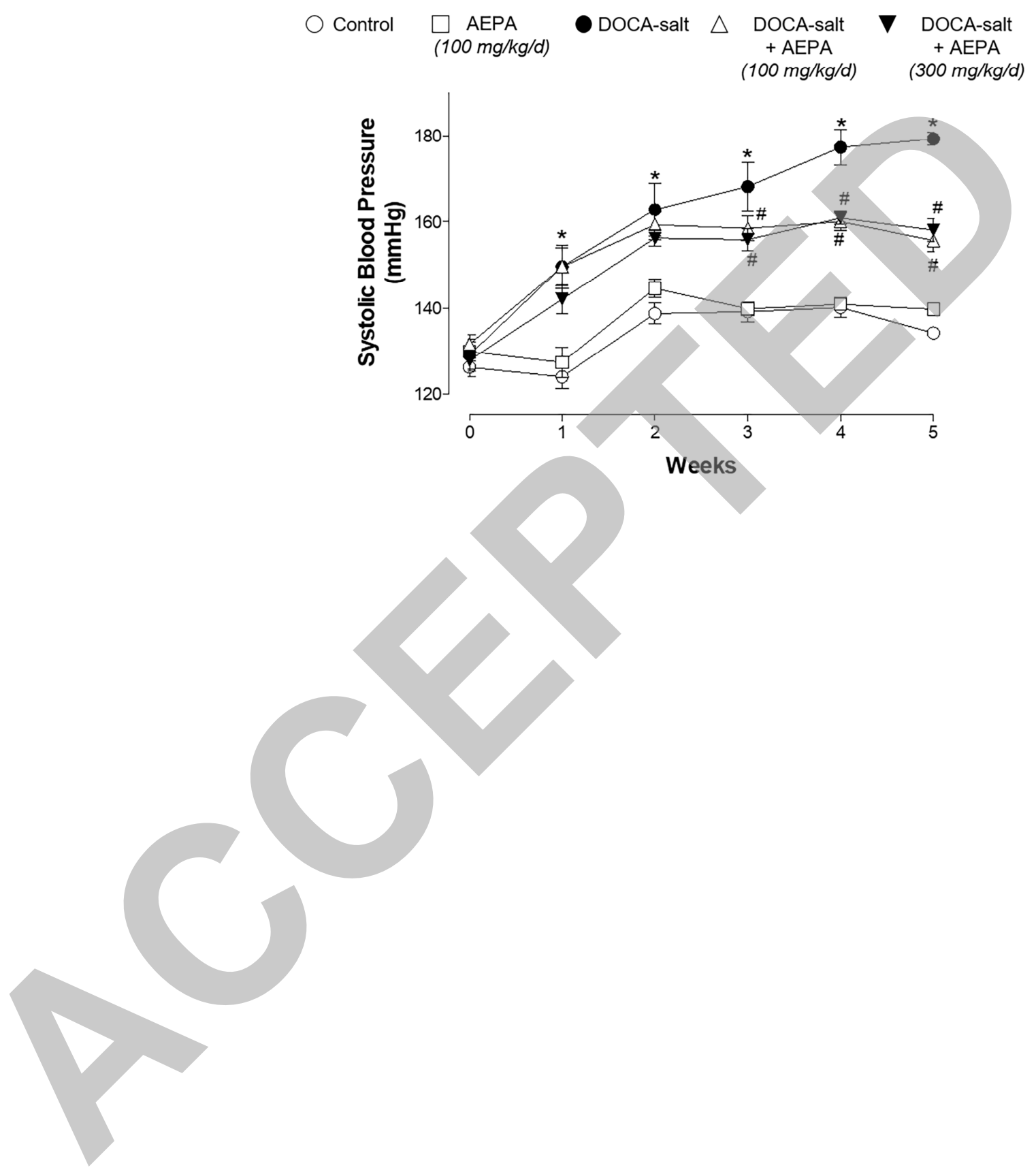


A

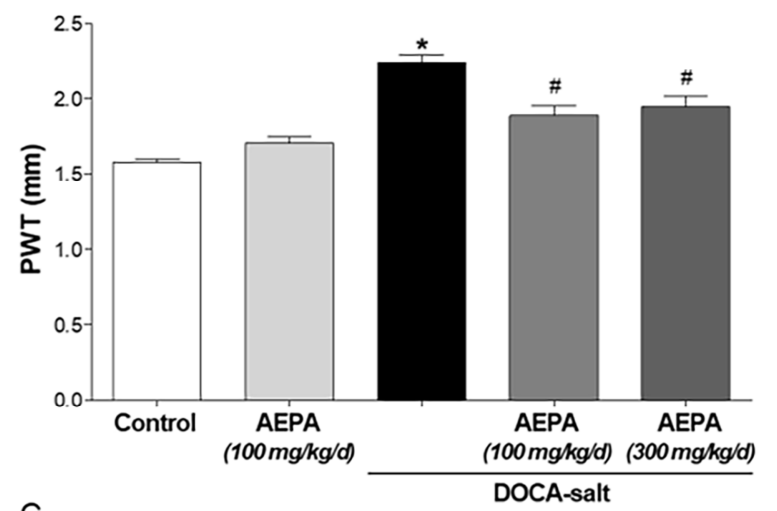

C

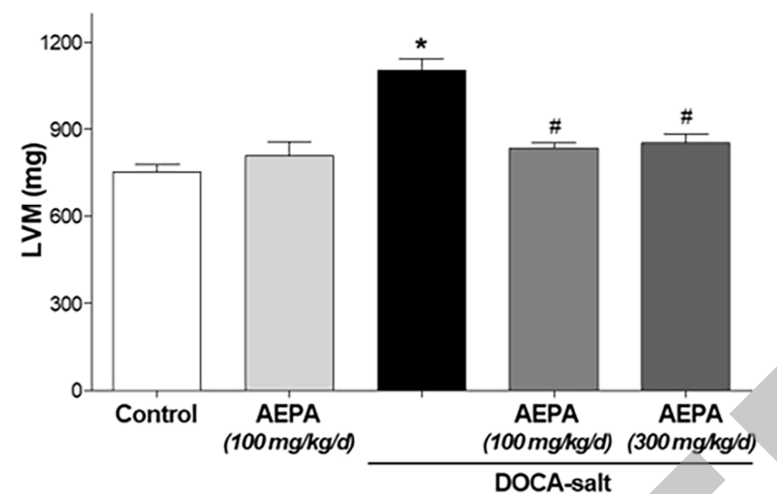

E

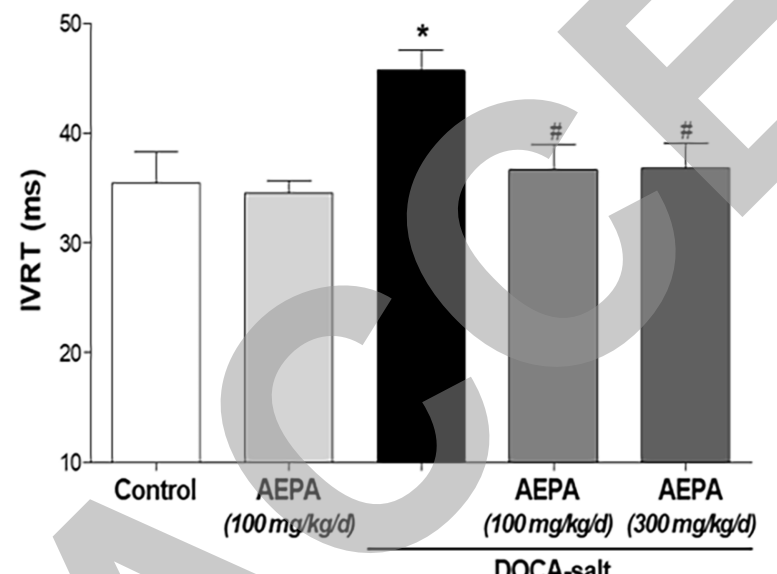

G

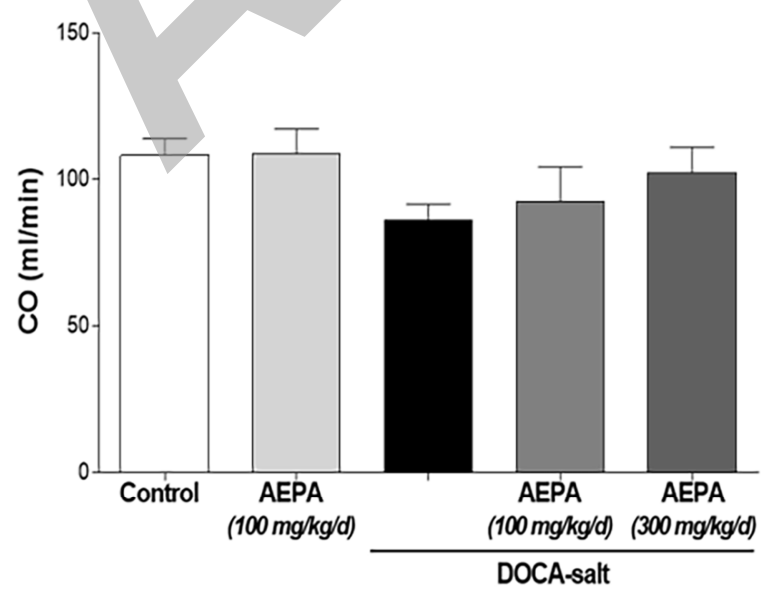

B
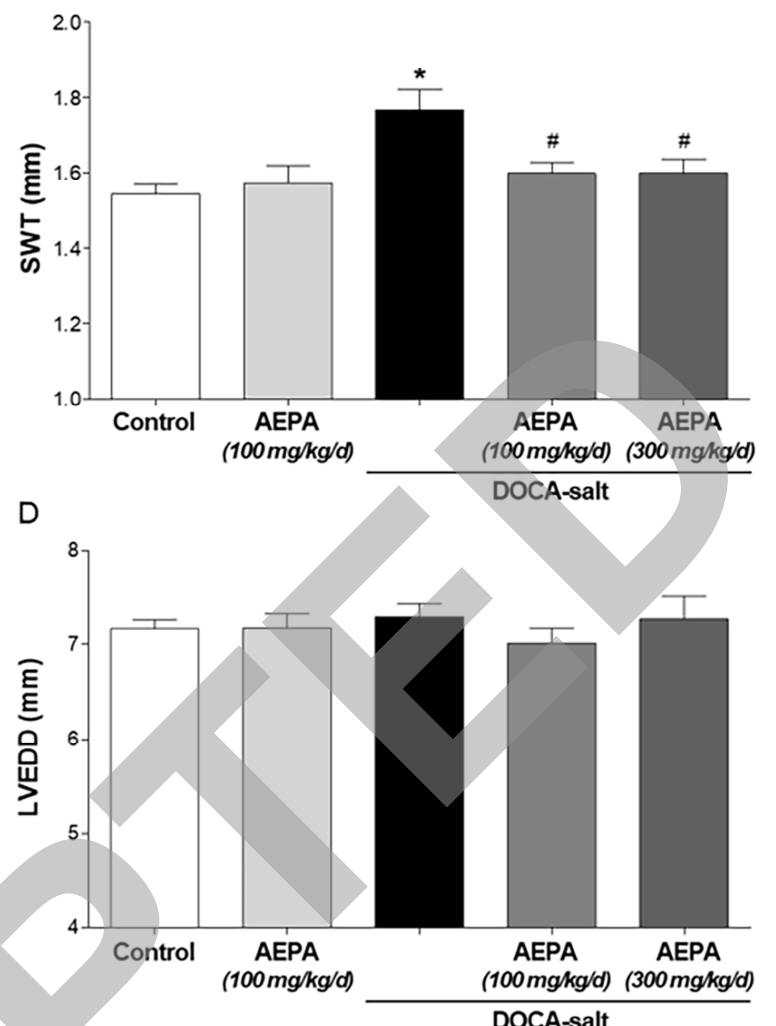

$\mathrm{F}$

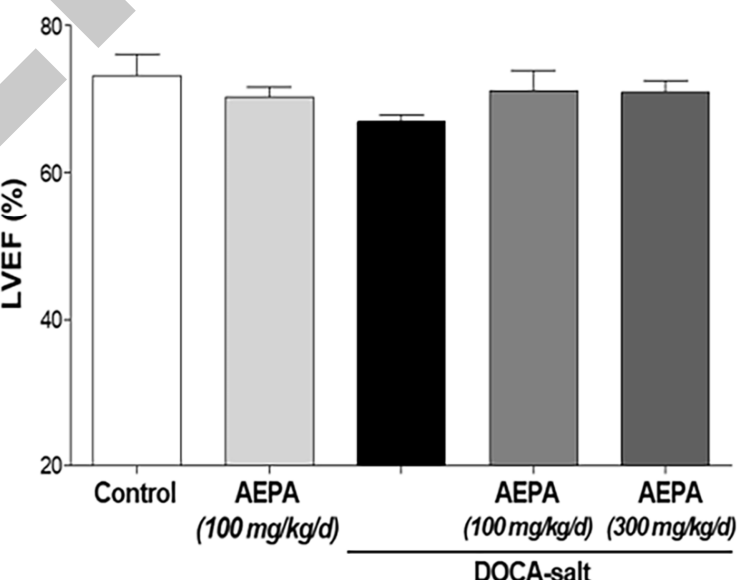

$\mathrm{H}$

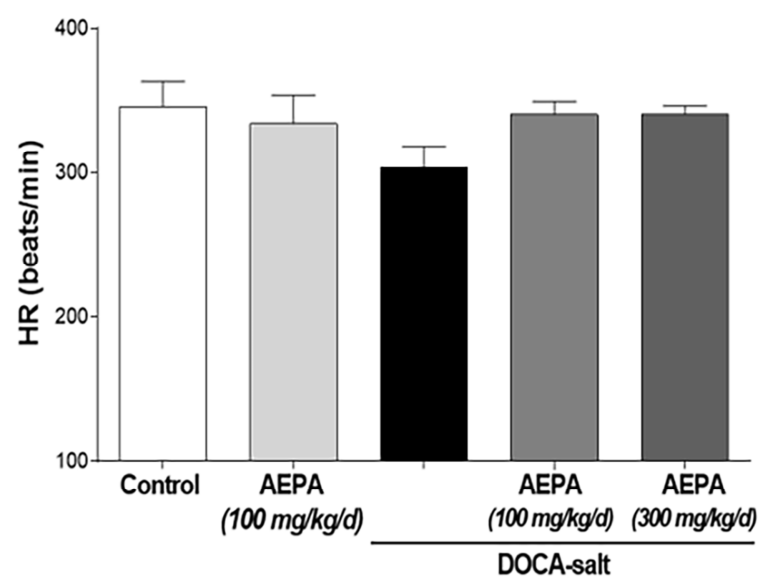


Figure 3

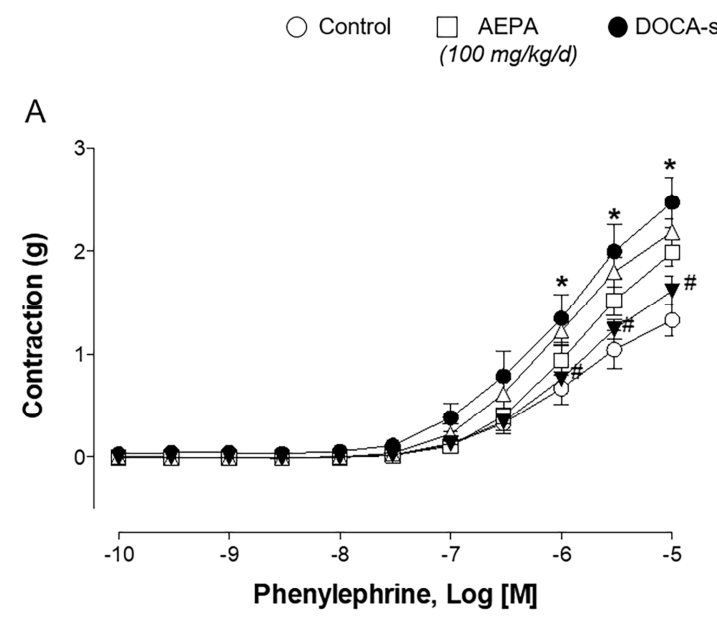
$\triangle$ DOCA-salt $\boldsymbol{\nabla}$ DOCA-salt
+ AEPA + AEPA

B

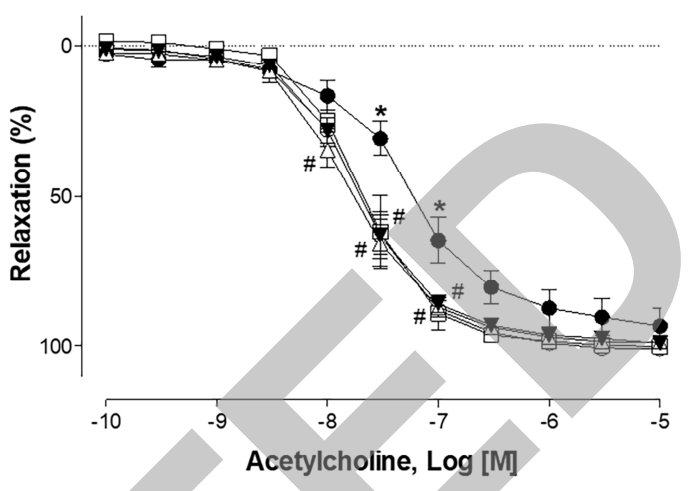


Figure 4

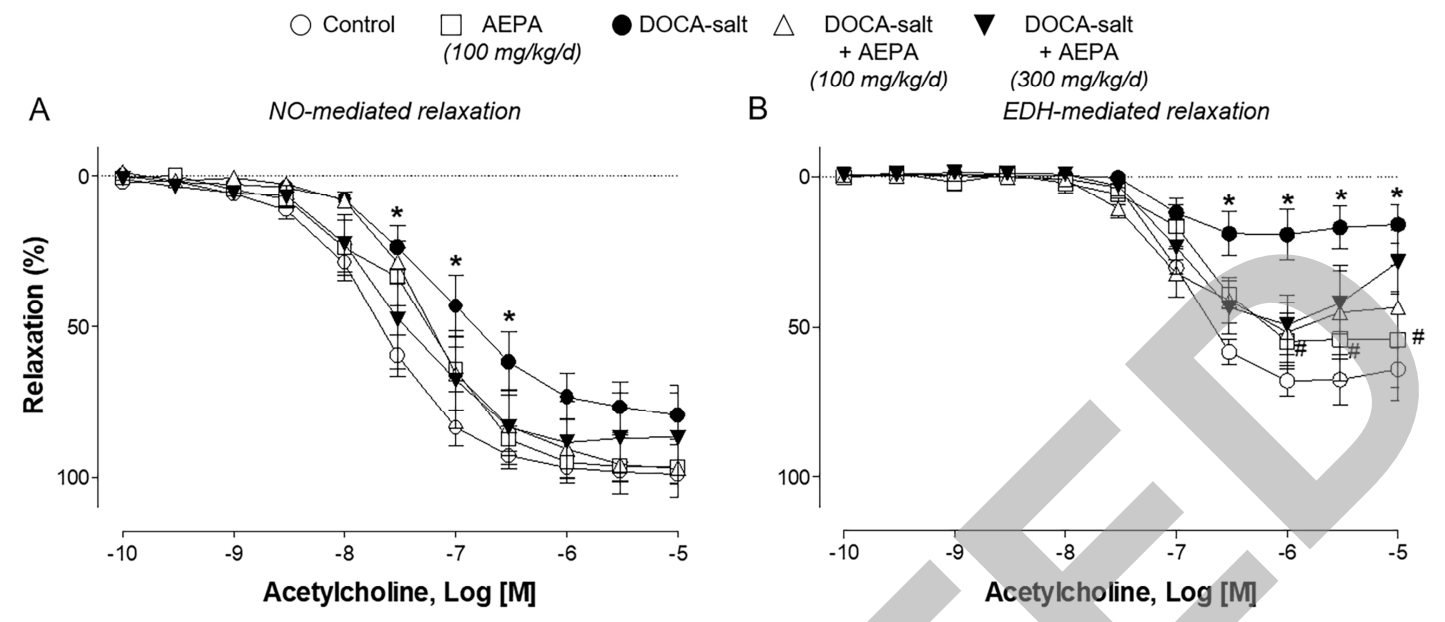


Figure 5

A
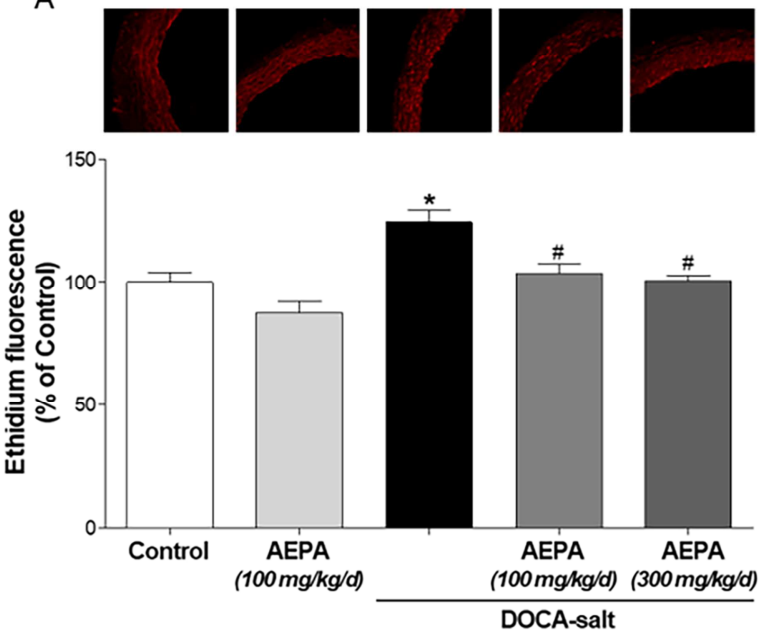

C
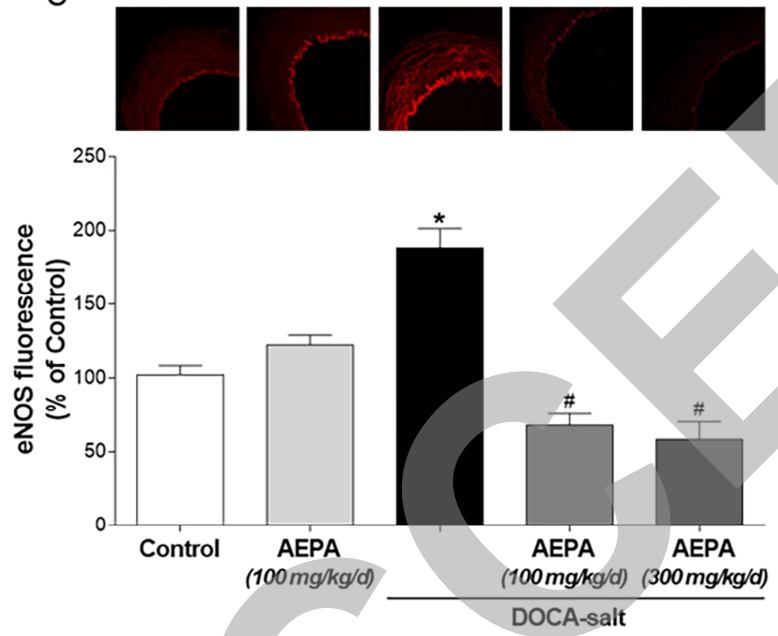

E
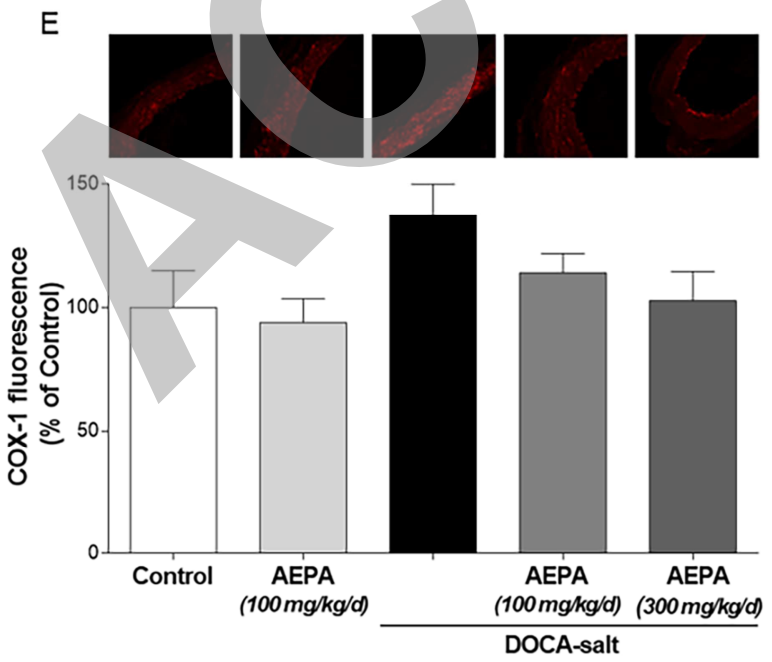

B
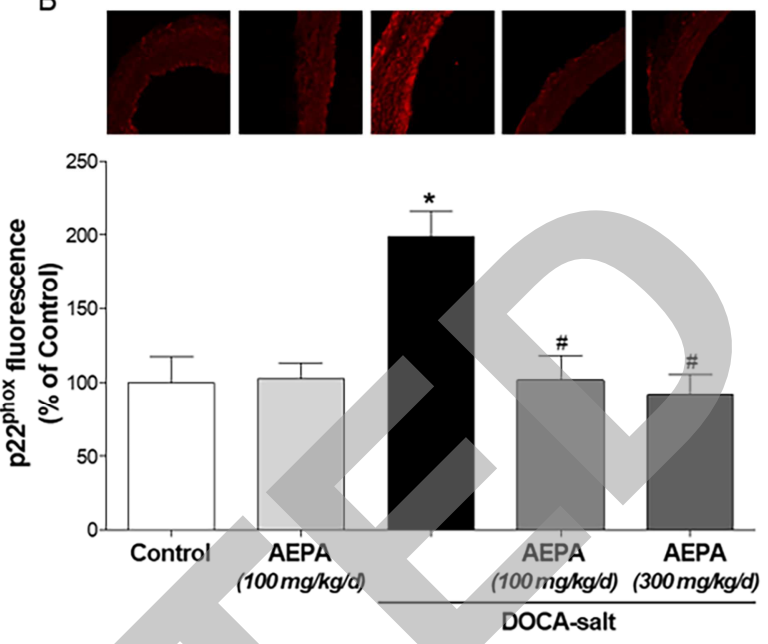

D

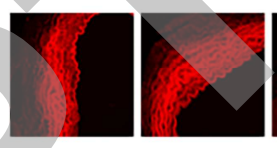

150

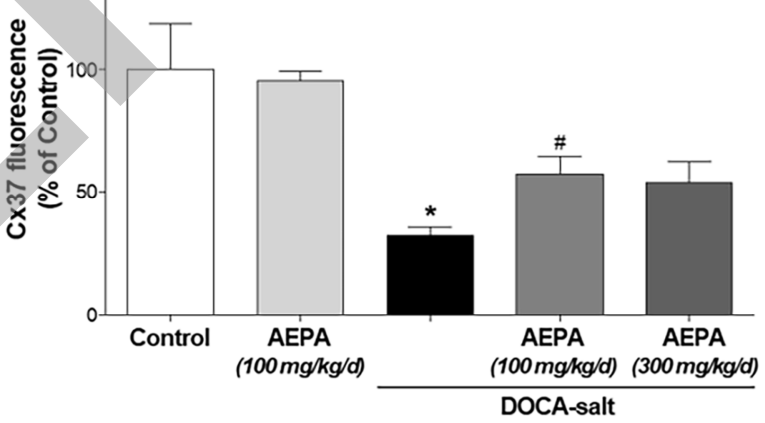

F
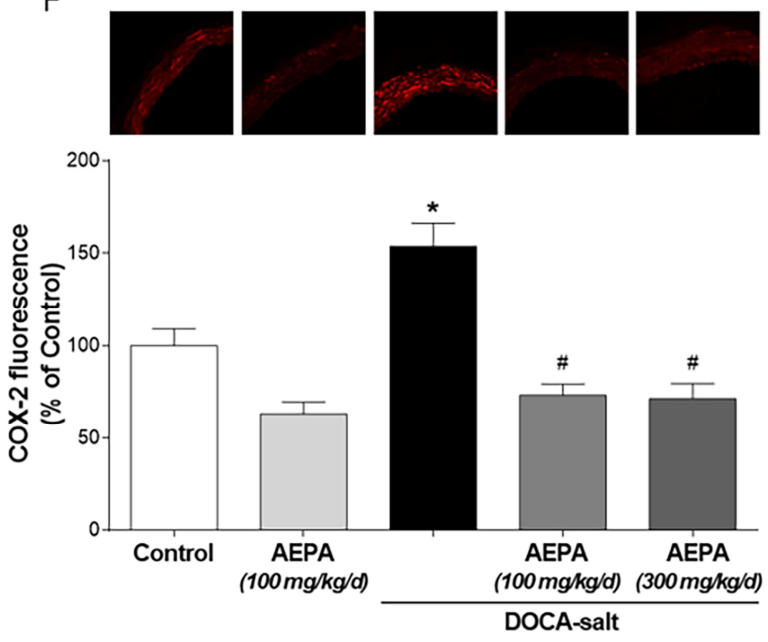